\title{
Endovascular Management of Paragangliomas
}

\author{
MOHAMED SHADAD, M.D., Ph.D. and AHMED ELSHARKAWY, M.D., Ph.D. \\ The Department of Neurosurgery, Faculty of Medicine, Tanta University
}

\begin{abstract}
Background: Paragangliomas of head and neck are highly vascular tumors, which coupled their surgical excision with high morbidity. Pre-operative transarterial super selective embolization markedly improved safety of their surgical excision.
\end{abstract}

Patients and Methods: This is a retrospective nonrandomized clinical and angiographic study of all ten patients with paragangliomas who undergone pre-operative embolization in Department of Neurosurgery-Tanta University between 2010 and 2016.

Results: The ten patients had 11 paragangliomas. $80 \%$ of patients were females. The average age of patients was 47 years. All patients had pain and pulsatile tinnitus at diagnosis. Paragangliomas subtypes comprised 8 temporal, 2 carotid body and one vagale tumors. The average reduction of paraganglioma vascularity after embolization was $80 \%$.

Conclusions: Pre-operative transarterial embolization of head and neck paragangliomas is a very safe and effective adjuvant to surgical excision.

Key Words: Paraganglioma - Embolization - Polyvinyl alcohol (PVA).

\section{Introduction}

PARAGANGLIOMAS, also known as glomus tumors, are highly vascular neoplasms, which arise from chemoreceptor cells of the paraganglia or glomus bodies. Paragangliomas rare tumors with incidence ranging from 1 in 30000 to 1 in 100000. In the head and neck, common sites involve carotid body, temporal bone (glomus tympanicum and glomus jagulare) and vagus nerve (glomus vagale) descending order of frequency. Usual age is fifth decade (younger in familial cases) with female predominance of 3:1 except for carotid body tumors. Multiplicity is common especially in familial cases $(10 \%$ in non familial versus $30 \%$ in familial cases) $[1-5]$

Correspondence to: Dr. Mohamed Shadad, The Department of Neurosurgery, Faculty of Medicine, Tanta University
Paragangliomas generally cause clinical symptoms by local bone invasion and infiltration of the bordering structures depending on tumor location. Carotid body tumors usually present as painless slowly growing neck mass. Temporal paragangliomas typically cause hearing loss, pulsatile tinnitus and cranial nerve palsy. Hormone secretion, lymph node involvement or metastases are unusual presentations for head and neck paragangliomas. The fish classification evaluates tumors on a scale of A through $\mathrm{D}$, with A representing localized tympanic tumor, B mastoid extension, $C$ erosion of the carotid canal (with subtypes), and $\mathrm{D}$ indicating intracranial extension $[3,6,7]$.

Radiological examinations are essential for accurate evaluation of paragangliomas and treatment planning. CT shows the extent of bone erosion. MRI shows the extent of tumor growth, vascular encasement and invasion of intracranial structures. MRI shows high velocity flow voids within the tumor giving the characteristic salt and pepper appearance. Conventional angiography typically shows enlarged feeding arteries, dense tumor vascular blush and early venous drainage. Paragangliomas are classically multicompartmental tumors. Each compartment has its own arterial feeder and draining vein requiring multiple superselective catheterizations to completely study or embolize the tumor $[\mathbf{8 , 9}$.

Available treatment options for head and neck paragangliomas comprise radiation therapy, surgical excision or combination of both. Surgical excision used to be associated with extreme morbidity due to excessive blood loss and cranial nerve palsy. Transarterial embolization is a proven treatment modality for pre-operative devascularization of these lesions to improve the situations under which surgery is executed. Nowadays, complete surgical resection of paragangliomas, after pre-operative embolization of external carotid feeders with PVA 
particles, has been the primary management plan leaving radiation therapy mostly for unresectable or residual tumors $[\mathbf{1 , 2 , 1 0 - 2 0 ]}$.

\section{Aim of the work:}

In this report, we evaluate safety and efficacy of pre-operative endovascular embolization of head and neck paraganglioma and present our experience with this procedure at Department of Neurosurgery, Tanta University, Egypt.

\section{Patients and Methods}

We included all patients with head and neck paraganglioma referred to us for pre-operative embolization between 2010 and 2016. All patients subjected to detailed history taking, complete clinical and neurological examination, audiometric evaluation, full laboratory investigations including 24-hour urinary catecholamine, and finally full radiological evaluation including $\mathrm{CT}$ and MRI scans.

Under general anesthesia standard trans-femoral approach were applied in all cases. Using $5 \mathrm{~F}$ multipurpose diagnostic catheter diagnostic angiography done in all cases to check tumor feeders and to define dangerous anastomosis with internal carotid and vertebral arteries. Evaluation of venous drainage and venous sinuses if invaded. Balloon occlusion test to evaluate collateral supply if ICA encased and there is possibility to sacrifice ICA.

Replacement with $6 \mathrm{~F}$ guiding catheter done in all cases. Combination of different microcatheters and microwires used according to diameter of feeders, target point of injection (selective or superselective), size of PVA particles intended for injection (150-1000 micron). Starting from 150 micron particles injected in pulsed manner targeting tumor bed until disappearance of the tumor blush while repeated control DSA repeated to check opening of dangerous anastomosis. Control DSA at the end to evaluate embolization done. Surgical excision preferred in first 48 hours post embolization.

\section{Results}

A total of 10 patients with 11 paragangliomas in the head and neck region underwent preoperative superselective arterial embolization of their lesion. Eight patients were females and 2 patients were males. The average age at presentation was 47 years old (range 31-57 years). Pain, pulsatile tinnitus and hearing loss were the most common clinical symptoms present at time of diagnosis in our series. Other clinical symptoms are listed in (Table 1). The average sizes of tumors at presentation are listed in (Table 2). Paragangliomas subtypes included eight temporal (tympanicum and jugulare), two carotid body and one vagale tumors.

The Ascending pharyngeal artery was the main arterial feeder for paragangliomas in all our cases. The inferior tympanic and neuromeningeal branches of the Ascending pharyngeal artery were the main feeders in temporal paragangliomas. Some of these temporal paraganglioma had supplementary feeders from occipital, the middle meningeal arteries, extradural branches of internal carotid artery and intradural branches with intracranial extension from internal carotid artery or vetebro-basilar system. The musculospinal branch of the Ascending pharyngeal artery was the main feeder of all carotid body tumors and vagal paraganglimas (Table 3 ).

Table (1): Presentations.

\begin{tabular}{lcc}
\hline Symptoms & No. & $\%$ \\
\hline Pain & 9 & 90 \\
Pulsatile tinnitus & 8 & 80 \\
Hearing loss & 6 & 60 \\
Vertigo & 4 & 40 \\
Pulsatile mass & 3 & 30 \\
Cranial nerve deficit & 2 & 20 \\
\hline
\end{tabular}

Table (2): Tumor size.

\begin{tabular}{lcc}
\hline Location & Range (in mm) & Median (in mm) \\
\hline Temporal & $15-60$ & 40 \\
Carotid body & $50-90$ & 70 \\
Vagale & 30 & 30 \\
\hline
\end{tabular}

Table (3): Arterial feeders.

\begin{tabular}{|c|c|c|}
\hline & No. & $\%$ \\
\hline \multirow{5}{*}{$\begin{array}{l}\text { Temporal paragangliomas: } \\
\text { - Inferior tympanic branch of Asc. pharyngeal } \\
\text { artery } \\
\text { - Neuromenigeal branch of Asc. pharyngeal artery } \\
\text { - Stylomastoid branch of occipital artery } \\
\text { - Caroticotympanic and cavernous braches of ICA } \\
\text { Pial branches of ICA and VBS }\end{array}$} & 8 & 100 \\
\hline & 8 & 100 \\
\hline & 4 & 50 \\
\hline & 2 & 25 \\
\hline & 2 & 25 \\
\hline \multirow{3}{*}{$\begin{array}{l}\text { Carotid body tumor: } \\
\text { - Musclospinal branch of ascending pharyngeal } \\
\text { artery } \\
\text { - Ascending cervical artery }\end{array}$} & & \\
\hline & 2 & 100 \\
\hline & 1 & 50 \\
\hline \multirow{3}{*}{$\begin{array}{l}\text { Vagal paragangliomas: } \\
\text { - Musclospinal branch of ascending pharyngeal } \\
\text { artery } \\
\text { - Muscular branches of occipital artery }\end{array}$} & & \\
\hline & 1 & 100 \\
\hline & 1 & 100 \\
\hline
\end{tabular}




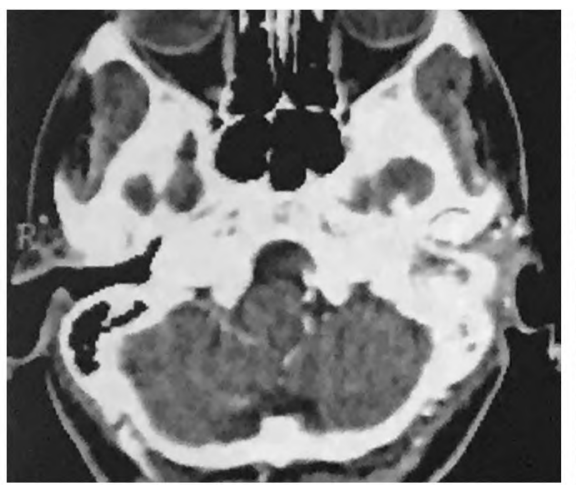

Enhanced CT showed LT temporal enhanced tumor mass

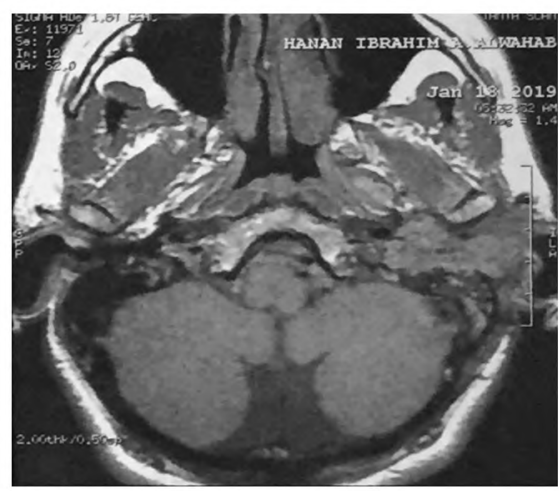

Enhanced MRI in axial and coronal views showed enhanced tumor mass and its relations to temporal bone and brain

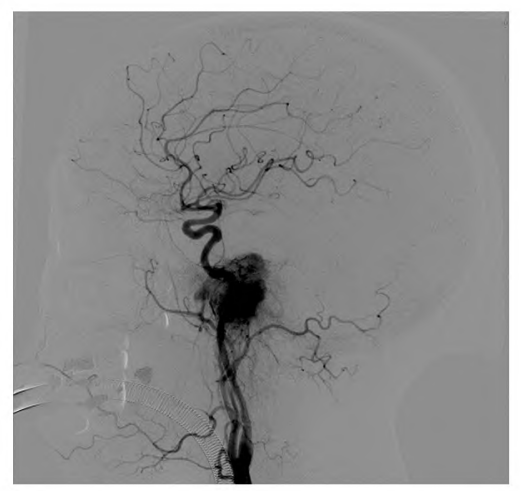

LT CCA Lat showed tumor blush

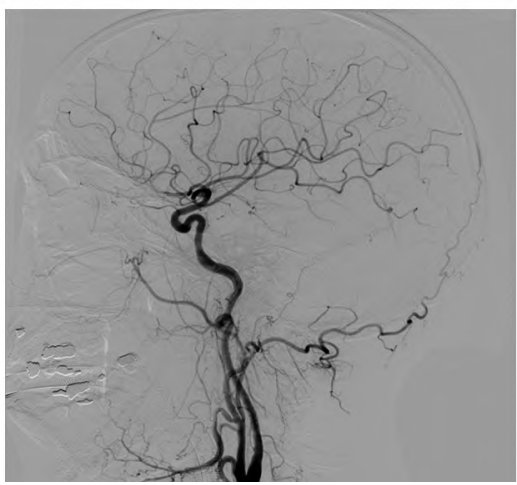

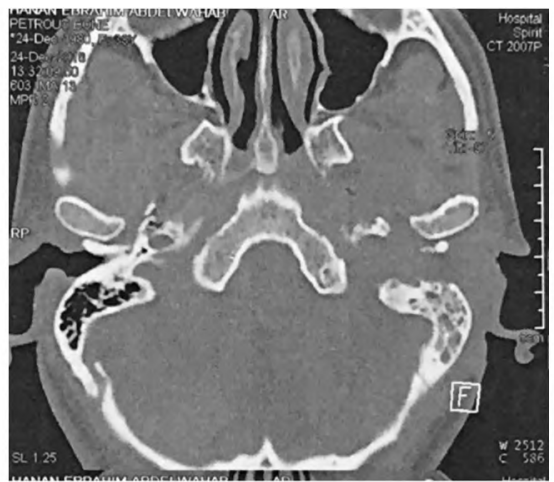

Bone window showed temporal bone erosion
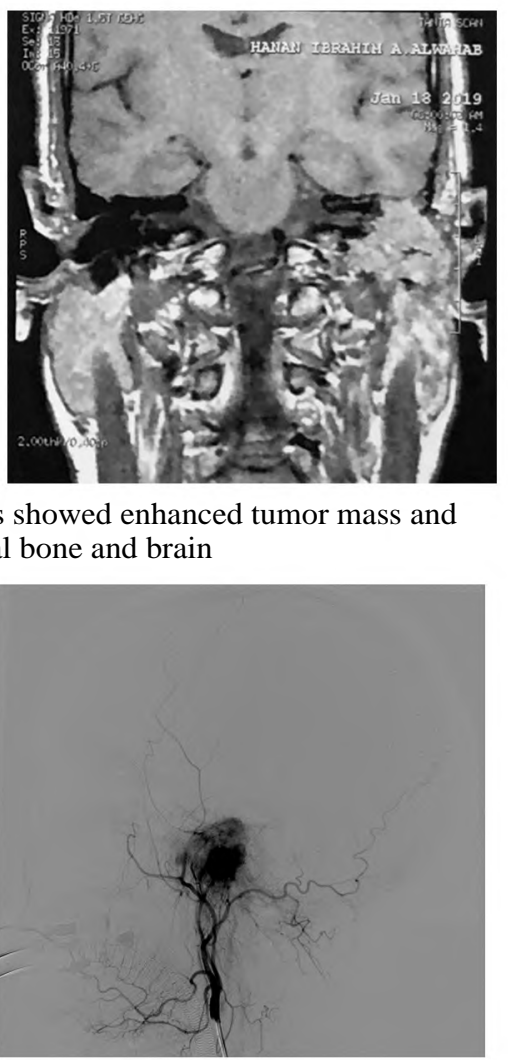

Selective ECA Lat showed tumor blush

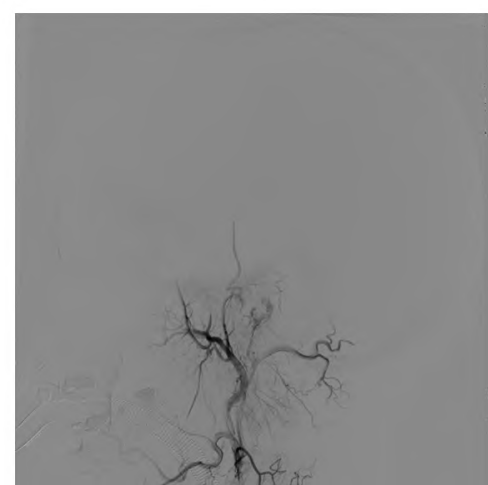

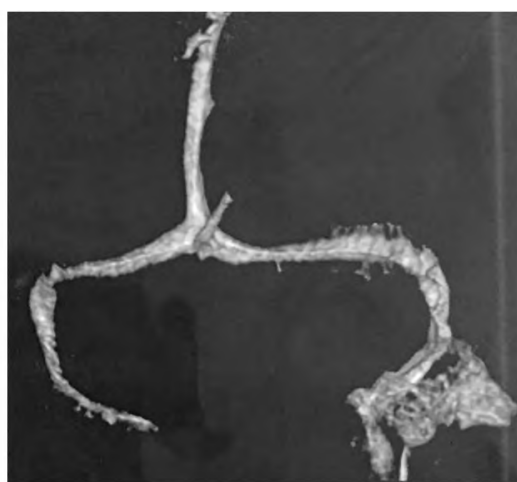

CT venography showed relation of tumor to sigmoid sinus

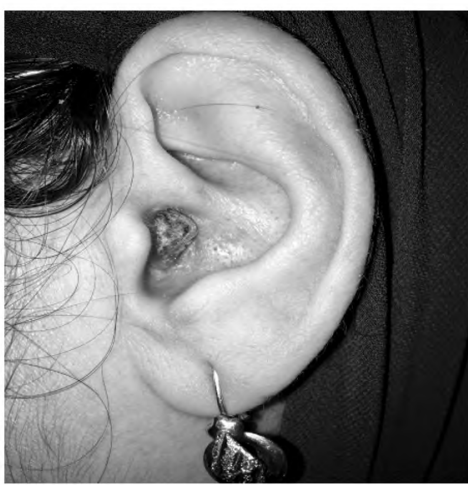

Pulsatile tumor mass protruding from left ear

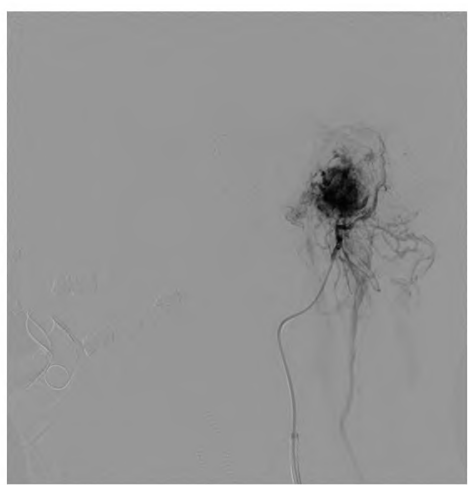

Superselective catheterization of Asc $\mathrm{Ph}$ A showed tumor blush

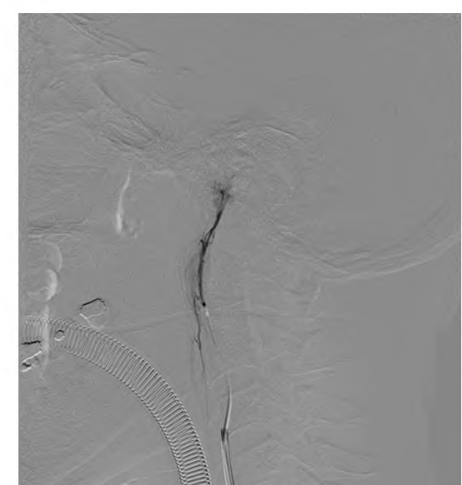

Control DSA from LT CCA, ECA, Asc Ph A showed total obliteration of tumor blush

Case (1): Female patient 45 years old had left temporal paraganglioma presented with pain, pulsatile tinnitus, left sided hearing loss and mass protruding from ear. CT bone window showed erosion of the temporal bone and enhanced CT and MRI showed tumor mass. Pre-operative super-selective transarterial embolization was done with total obliteration of tumor blush. 


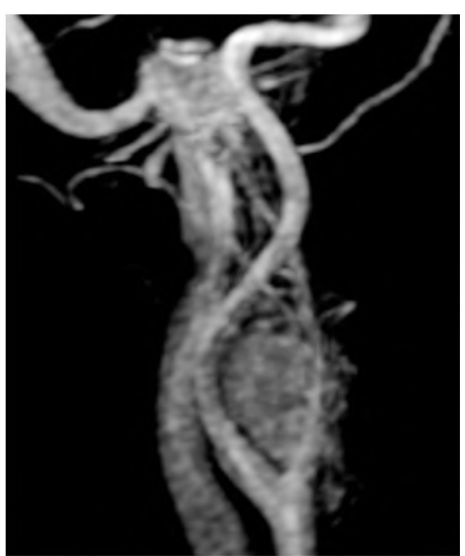

MRA showed tumor blush

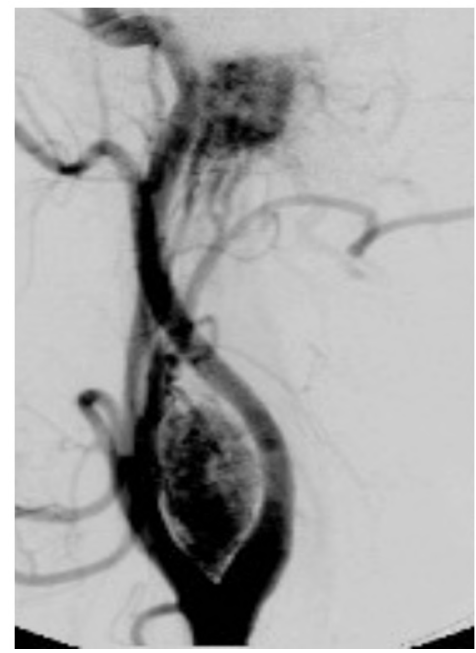

RT CCA showed tumor blush in both location jugular and carotid body

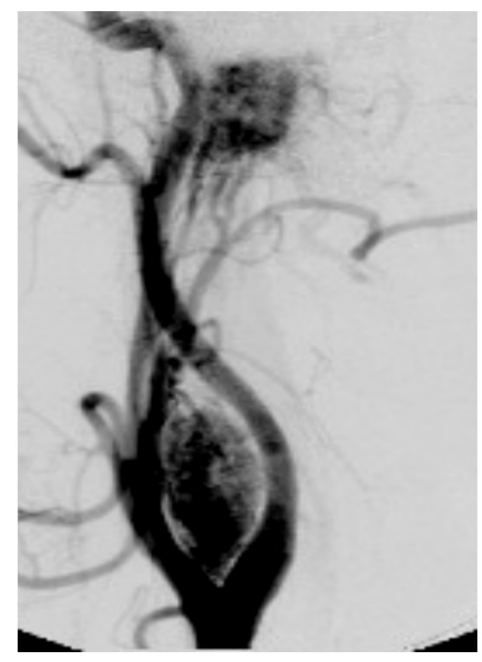

RT CCA showed tumor blush in both location jagular and carotid body
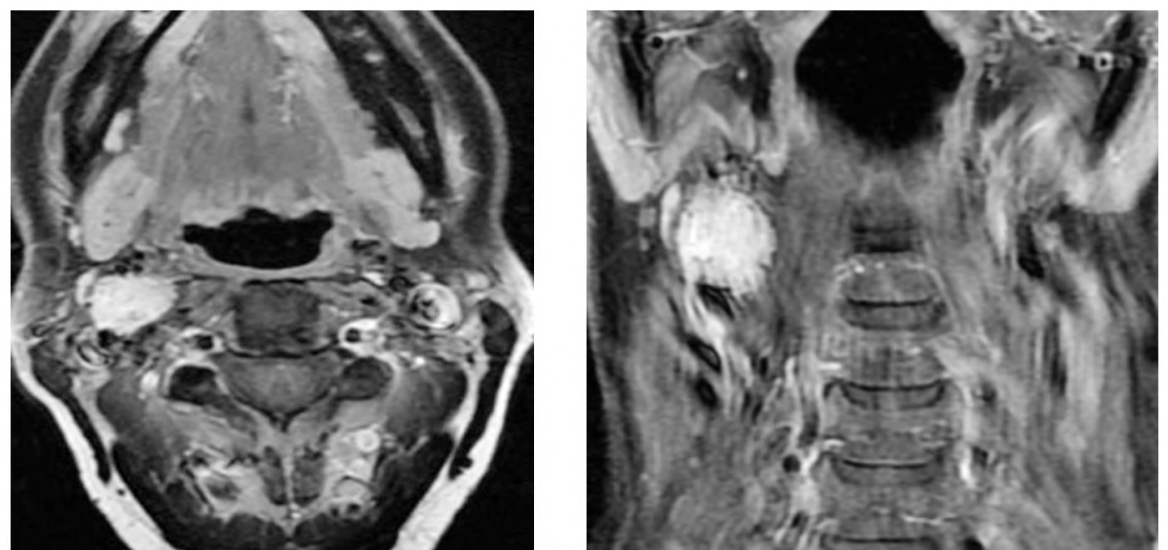

Enhanced MRI axial and sagittal views showed tumor mass in jugular fossa
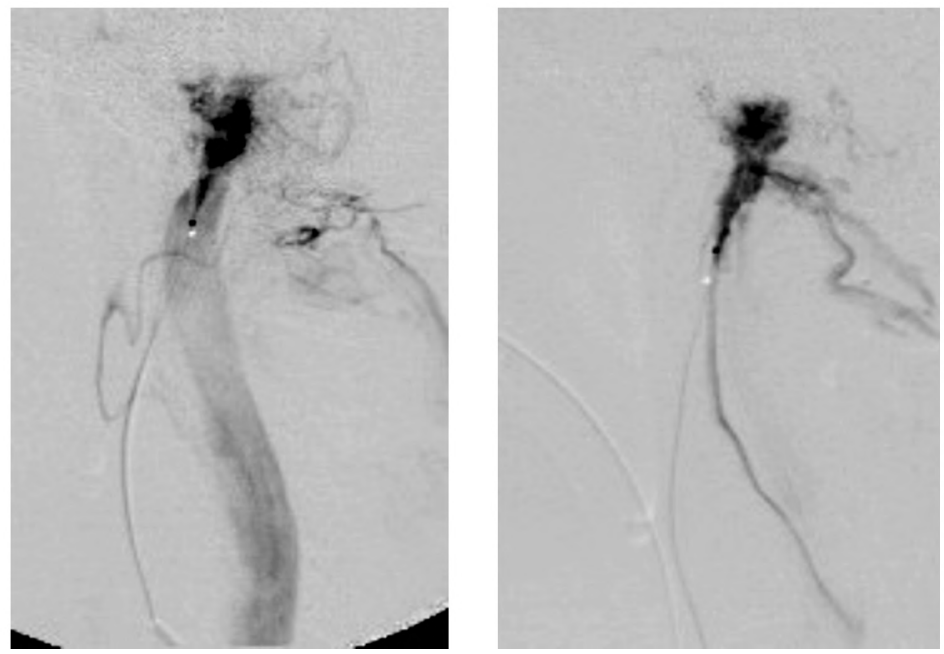

Super-selective injection from inferior tympanic and neuromeningeal branches of Asc $\mathrm{Ph}$ A showing tumor blush in jugular location
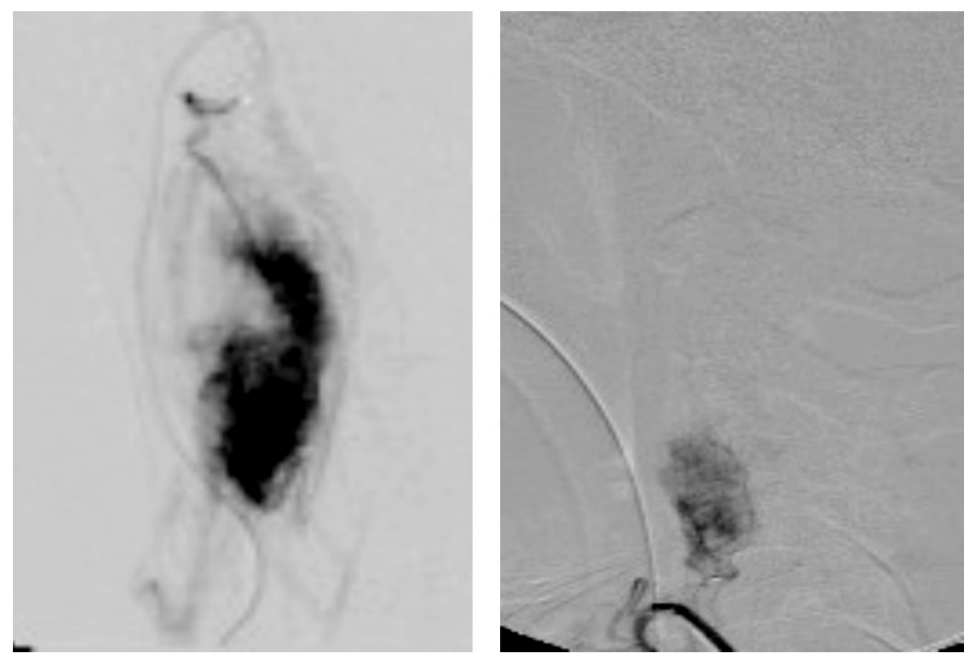

Super-selective injection from muculospinal branchs of Asc Ph A showing tumor blush in carotid body location 


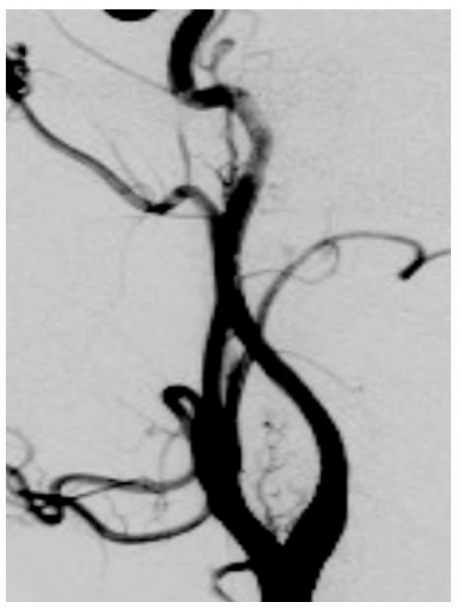

Control DSA from RT CCA showing total obliteration of tumor blush in both locations
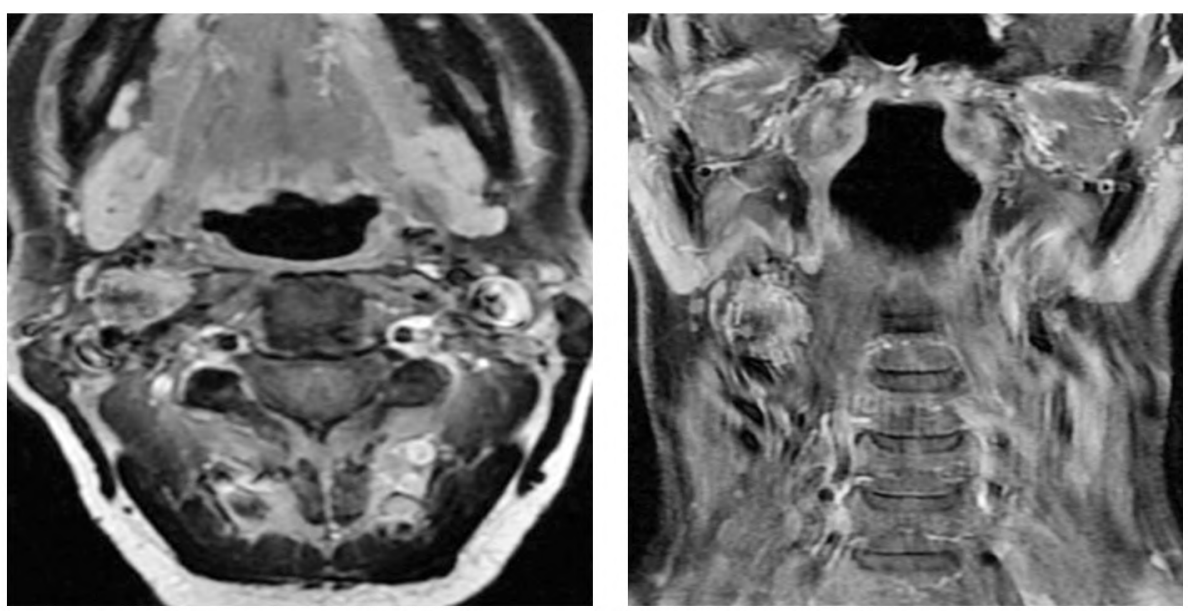

Post embolization enhanced MRI showing central necrosis of tumor mass in jugular fossa

Case (2): Female patient 48 years old with multifocal paraganglioma (jagular fossa and carotid body) presented with painful neck swelling and pulsatile tinnitus. Enhanced MRI showed tumor in both locations. Pre-operative super-selective transarterial embolization was done with total obliteration of tumor blush in both locations.

Total and subtotal (90-100\%) disappearance of tumor blush achieved in 8 patients while incomplete (60-89\%) disappearance of tumor blush achieved in two patients. Necrosis evaluated by absent enhancement or decrease of contrast uptake in post embolization contrast CT and MRI.

No permanent morbidity or mortality in our series. All patients had transient mild post embolization pain that resolve with steroids and analgesics. Femoral artery dissection without sequel occurred in 1 patient with sheath insertion and sealed by blood flow and prophylactic anticoagulation given with normal Duplex study in second post-operative day. Surgical reports, of our series, showed dramatic effect of pre-operative embolization on limiting the amount of intraoperative blood loss and decreasing neurologic morbidity during surgical excision of paraganglioma. The average intraoperative blood loss was $900 \mathrm{ml}$ for glomus jugular, $500 \mathrm{ml}$ for carotid body and $600 \mathrm{ml}$ for glomus vagale.

\section{Discussion}

Most common locations for paragangliomas in our study included temporal location (middle ear and jugular fossa) in $80 \%$, carotid body location in $20 \%$ and vagal location in $10 \%$. The incidence of paraganglioma subtypes in our series is close to that reported in the larger series of 224 head and neck paragangliomas by Papaspyrous et al. They had 53\% temporal paragangliomas, 30\% carotid body tumors and $12 \%$ glomus vagale tumors [21].
In our study 1 patient have multifocal paraganglioma including temporal and carotid body locations. Multifocal head and neck paraganglioma have been reported in 10-20\% of sporadic cases with higher incidence up to $80 \%$ in familial cases [4].

Hormonal activity of head and neck paragangliomas is very rare (1\%-3\%). No one of our patients had clinical or biochemical evidence of hormonal activity of their paragangliomas. No history of hypertensive crisis or increased 24-hour urine catecholamine excretion. Papaspyrous et al., had only one of their 175 patients, with head and neck paragangliomas, who showed evidence of excess catecholamine excretion [21,22].

There is still much debate about the optimal treatment for head and neck paragangliomas. These lesions are almost benign with very slow rate of growth. It takes almost ten years for a paraganglioma to double in size. This natural history gives logic for watchful conservative treatment in the elderly. Radiotherapy allows good control of paraganglioma growth and offers the patient a worthy chance to preserve neurologic function and good quality of life for a long period of time especially for those with multiple lesions. Surgical resection is still the only option for complete reliable eradication of paraganglioma. Microsurgical techniques and pre-operative embolization are important adjuvant to improve visualization, reduce operative blood loss and neurologic morbidity [22-24]

Our embolization strategy is to perform superselective catheterization of the main feeding artery 
and to perform intra-tumoral embolization starting with small size particles (150-250) and gradually increasing the particle size. We aim, by embolization on tumor bed level, to control the blood flow from dangerous supplementary feeding arteries without catheterizing them. We always keep in mind the risk of paradoxical embolization of the brain or cranial nerves through potential anastomosis with internal carotid or vertebro-basilar arteries. So, we avoid the use of very small particle size (smaller than 100 micron), which can shunt through these dangerous anastomosis. We also perform frequent intermediate angiographic control for early detection of opening of such anastomosis.

Post embolization enhanced images, intraoperative blood loss and histopathological examination of the resected specimen showed necrosis in most of cases with pre-operative embolization that confirms the effects of pre-operative embolization. Surgical reports, of our series, showed dramatic effect of pre-operative embolization on limiting the amount of intraoperative blood loss and decreasing neurologic morbidity during surgical excision of paraganglioma. This goes with the results of White et al., who had no evidence of neurological complications after pre-operative embolization of 38 head and neck paragangliomas. They also reported decrease of intraoperative blood loss and neurological complications during surgical excision [25].

No permanent morbidity or mortality related to endovascular embolization of paraganglioma in our series apart from one patient with silent small dissection in femoral artery and transient post embolization pain at the tumor site, which resolved within 48 hours with analgesics and steroids. Postembolization ear pain has been reported in other series and were related to tumor ischemia $[2,12]$.

\section{Conclusion:}

The outcome of patients in our study shows that pre-operative embolization of head and neck paraganglioma is a very safe and effective adjuvant to surgical excision.

\section{References}

1- BOEDEKER C.C., G.J. RIDDER and J. SCHIPPER: Paragangliomas of the head and neck: Diagnosis and treatment. Fam. Cancer, 4 (1): p. 55-9, 2005.

2- MILUNSKY J.M., et al.: Novel mutations and the emergence of a common mutation in the SDHD gene causing familial paraganglioma. Am. J. Med. Genet., 100 (4): p. 311-4, 2001.
3- LEE J.H., et al.: National Cancer Data Base report on malignant paragangliomas of the head and neck. Cancer, 94 (3): p. 730-7, 2002

4- DUNDEE P., et al.: Paraganglioma: The role of genetic counselling and radiological screening. J. Clin. Neurosci., 12 (4): p. 464-6, 2005.

5- VALAVANIS A.: Pre-operative embolization of the head and neck: Indications, patient selection, goals, and precautions. A.J.N.R. Am. J. Neuroradiol., 7 (5): p. 943-52, 1986.

6- FISCH U.: Infratemporal fossa approach for glomus tumors of the temporal bone. Ann. Otol. Rhinol. Laryngol., 91 (5 Pt 1): p. 474-9, 1982.

7- SARINGER W., et al.: Paragangliomas of the temporal bone: Results of different treatment modalities in 53 patients. Acta Neurochir (Wien), 144 (12): p. 1255-64; discussion 126, 2002.

8- VAN DEN BERG R.: Imaging and management of head and neck paragangliomas. Eur. Radiol., 15 (7): p. 13108, 2005.

9- BERENSTEIN A.: [Life crises]. Rev. Enferm., 24 (6): p. $441,2001$.

10- KASPER G.C., et al.: A multidisciplinary approach to carotid paragangliomas. Vasc. Endovascular. Surg., 40 (6): p. 467-74, 2006.

11- GUJRATHI C.S. and P.J. DONALD: Current trends in the diagnosis and management of head and neck paragangliomas. Curr. Opin. Otolaryngol. Head Neck Surg., 13 (6): p. 339-42, 2005.

12- LASJAUNIAS P., et al.: Non chromaffin paragangliomas of the head and neck. Diagnostic and therapeutic angiog raphy in 19 cases explored from 1977 to 1980 . J. Neuroradiol., 8 (4): p. 281-99, 1981.

13-FISCH U., P. FAGAN and A. VALAVANIS: The infratemporal fossa approach for the lateral skull base. Otolaryngol. Clin. North Am., 17 (3): p. 513-52, 1984.

14- LAS SEN-RAMSHAD Y., et al.: Paraganglioma of the head and neck region, treated with radiation therapy, a Rare Cancer Network study. Head Neck, 41 (6): p. 17706, 2019.

15- DUPIN C., et al.: Treatment of head and neck paragangliomas with external beam radiation therapy. Int. J. Radiat. Oncol. Biol. Phys., 89 (2): p. 353-9, 2014.

16- TASAR M. and S. YETISER: Glomus tumors: Therapeutic role of selective embolization. J. Craniofac. Surg., 15 (3): p. 497-505, 2004.

17- DUFFIS E.J., et al.: Head, neck, and brain tumor embolization guidelines. J. Neurointerv. Surg., 4 (4): p. 251-5, 2012.

18-PERSKY M.S., et al.: Combined endovascular and surgical treatment of head and neck paragangliomas--a team approach. Head Neck, 24 (5): p. 423-31, 2002.

19- MYSSIOREK D.: Head and neck paragangliomas: An overview. Otolaryngol. Clin. North Am., 34 (5): p. 829$36, \mathrm{v}, 2001$.

20- TIKKAKOSKI T., et al.: Pre-operative embolization in the management of neck paragangliomas. Laryngoscope, 107 (6): p. 821-6, 1997. 
21- PAPASPYROU K., et al.: Head and neck paragangliomas: Report of 175 patients (1989-2010). Head Neck, 34 (5): p. 632-7, 2012.

22- PAPASPYROU K., W.J. MANN and R.G. AMEDEE: Management of head and neck paragangliomas: Review of 120 patients. Head Neck, 31 (3): p. 381-7, 2009.

23- HUY P.T., et al.: Evolving concepts in the management of jugular paraganglioma: A comparison of radiotherapy and surgery in 88 cases. Skull Base, 19 (1): p. 83-91, 2009.

24- GJURIC M. and M. GLEESON: Consensus statement and guidelines on the management of paragangliomas of the head and neck. Skull Base, 19 (1): p. 109-16, 2009.

25- WHITE J.B., M.J. LINK and H.J. CLOFT: Endovascular embolization of paragangliomas: A safe adjuvant to treatment. J. Vasc. Interv. Neurol., 1 (2): p. 37-41, 2008.

\section{إستخدام القسطرة المخية فى علاج الآورام الظهارية}

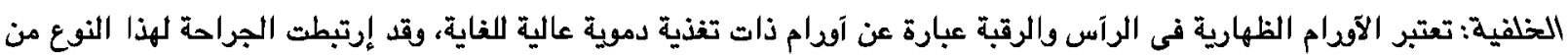

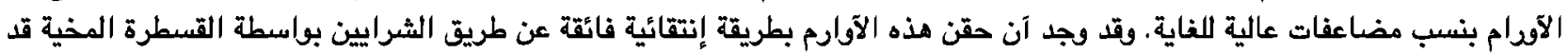
آدى إلى تحسن النتائج الجراحية.

الهدف: تهدف هذه الدراسة إلى تقيّم سلامة وكفاءة إستخدام القسطرة المخية فى غلق التفذية الدموية قبل إجراء الجراحة للآودام الظهارية في الرآس والرقبة.

الطرق : هذه الدراسة بآثر رجعى لجميع المرضى العشرة الذين يعانهن من الآقرام الظهارية في الرآس والرقبة الذين خضعوا للحقن قبل

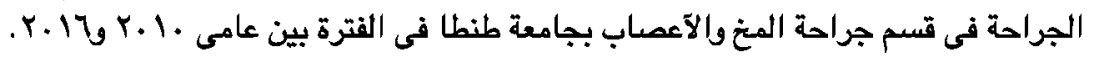

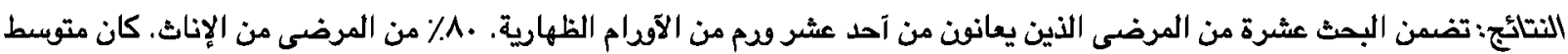

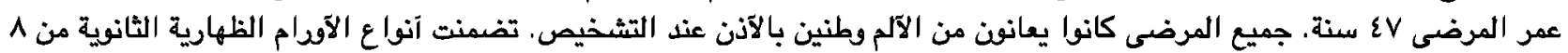

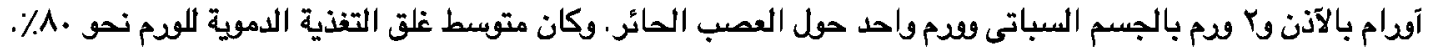
الإستتاجات: إستخدام القسطرة المخية في غلق التغذية الدموية قبل إجراء الجراحة للآقدام الظهارية في الرآس والرقبة هووسيلة مساعدة

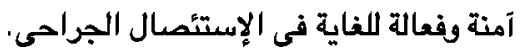

